International Journal of Linguistics, Literature and Translation

ISSN: 2617-0299 (Online); ISSN: 2708-0099 (Print)

DOI: 10.32996/ijltt

Journal Homepage: www.al-kindipublisher.com/index.php/ijltt

\title{
A Semiotic Analysis of Novel Faces in Hot Water by Abdallah Tayeh
}

\author{
Said Mohammed Al-Fayoumi ${ }^{1} \mathbf{8}$ (D) and Nadira Brioua ${ }^{2} \mathbf{8}$ (D) \\ ${ }^{1}$ Professor of Arabic Literature at Al-Quds Open University, Palestine \\ ${ }^{2}$ Ph.D., Department of English Language and Literature, International Islamic University Malaysia, Malaysia
}

$\triangle$ Corresponding Author: Nadira Brioua, E-mail: nadirabrioua39@gmail.com

\section{ARTICLE INFORMATION ABSTRACT}

Received: March 15, 2021

Accepted: April 18, 2021

Volume: 4

Issue: 4

DOI: $10.32996 /$ ijllt.2021.4.4.9

\section{KEYWORDS}

Semiotics, signs, novel cover, the title, characters, settings, Faces in Hot Water
The aim of this study is to investigate the semiotics of the cover, title, characters and the settings of Faces in Hot Water (1996) by the Palestinian writer Abdallah Tayeh. The study shows how important is semiotics in aesthetically and cognitively shaping the novel. The study adopts a qualitative research method by applying semiotic analysis to create a new understanding of the literary text and its interpretations. Built on semiotic analysis, the writer embodies the prevailing norms, traditions and culture of the Palestinian society. The writer also reveals semantic signs that are not visible. He in fact captured the implied meaning behind the semiotic text. The research shows that Tayeh uses many semiotic signs to refer to the various concepts of issues related to the Palestinian culture, society and beliefs.

\section{Introduction}

Abdullah Tayeh published Faces in Hot Water in its first edition by the Palestinian Writers Union in 1996. This novel chronicles the period leading up to the Palestinian Intifada (uprising). The novel is divided into fourteen paragraphs arranged in a sequential/chronological order to address the vast range of Palestinian social and political issues. It deals with the issue of Palestinian workers working inside the territories of occupied Palestine in 1948. The writer narrates the suffering that Palestinian workers have faced while working with/for their Israeli masters, since the relationship is based on ethnicity and race. Throughout the novel, the author further refers to many issues, including the nature and structure of the "other" Jewish personality characterized with racism and the dimension and depth of the chasm between the Eastern and the Western Jews as shown in the attitudes of the two characters, Ezra and Shmueli.

Since the fifties of the last century, semiotics has formed an intellectual theory that has enriched contemporary critical thinking and provided it with new methods to understand and interpret the text in all its forms, and in particular the literary text. At the beginning of the last century, the American philosopher, Charles Sanders Peirce and the Swiss linguist, Ferdinand De Saussure established a new field of science of signs called semiotics. Semiotics or semiology was defined by De Saussure as the study of "the life of signs within society" (Bengrad, 2003, p. 1). So, the goal of semiotics as a method, based on its definition, is to give us a new knowledge for a better understanding of social life in its social aspect Peirce and De Saussure reported that semiology has an impact on cognitive awareness and other sciences in general, especially those related to literature and arts. Semiology has significantly contributed to the renewal and development of critical consciousness by linking meaning to the (non) literary realm.

Adopting a semiotic analysis approach, this study investigates the signs implied by the title, characters, and setting of Tayeh's novel; Faces in Hot Water. The author attempts to find the semiotic sings entailed by the novel.

Furthermore, the author portrays a set of topics with progressive goals i.e., the strike announced by the Palestinian workers against their Jewish masters. Although a group of Palestinians were dismissed due to the strike, intifada and resistance against Jewish employer were obviously an indication of a new-born Palestinian uprising. However, the strike did not take long time since Palestinians sought livelihood to feed their families. Tayeh also depicts another picture of exploitation represented through

\section{K C AL-KINDI CENTER \\ $\mathbf{R}$ D FOR RESEARCH AND DEVELOPMENT}

Your gateway to world-class research

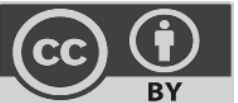

Published by Al-Kindi Center for Research and Development, London, United Kingdom. Copyright (c) the author(s). This open access article is distributed under a Creative Commons Attribution (CC-BY) 4.0 license 
the Palestinian character Abu Ali, the contractor of the boy workers. The writer starts the story with narrating the miserable conditions that Palestinians were living in Shuja'iyya and Al-Shati Camp. He finally narrates the intifada, which was an expected reaction due to Israeli merciless oppression and exploitation against the indigenous Palestinians living in their land over centuries.

Having portrayed the oppression, exploitation and suffering that the Palestinian workers went through, Tayeh narrates how Palestinian workers could be economically independent. Ismail al-Ajmawi as a character, for instance, changes his job to end up with weaving factory. Having changed his room into a shop to sell fruits and vegetables at Al-Shati Camp, Sabri Abu was having a self-monologue that

Why not demolish the facade of the room, overlooking the street, to become a store like the rest of the market shops. From this room I shall sell vegetables and fruits until I return to work after the vacation is to be expired. If I return, my wife, will use it; and if Shmueli fires me, I shall use it until I find a job. (Tayeh, 1996, p. 19)

Having conceptualized the novel, the writer plotted the story in his mind in line with the goals to be achieved. These goals usually sympathetically represent the themes and the general issues that the novel deals with. Nevertheless, other objectives concerning the writer's sub-consciousness ideas should not be neglected since it entails the cover, special title, names of the characters, time and geographic location within a narrative. So that, such specific choices in the selected text are the core of our study in this paper.

This research entitled "Semiotic Analysis of Novel Faces in Hot Water by Abdallah Tayeh" studies the semiotics of both the cover and title of the selected work to indicate their interaction and combination as signs to meet the meaning in the narrative text. It also studies the characters' signs represented in the novel in relation to the semiotics of the characters' names and narrative function. It also examines the extent the name fits (goes perfectly with) the function. Finally, it explores the novel semiotics concerning settings, time, and the role of these elements in embodying a large part of the writer's consciousness to shape the narrative space.

\section{Title's Semiotic Analysis}

The semiologists have paid special attention to the title in literary texts and considered it as a successful technique in interpreting the text. In this context, Roman Jacobson (as cited in Tankoul, 1987, p. 135) mentioned three basic functions of the title "referential, connotative and phatic." Gerald Genette suggested four basic functions of the title seductive, designation, descriptive and connotative. Other functions, however, branch out according to the gender of the literary text (Hamdaoui, 1997, pp. 98-99). Similarly, Muhammad Miftah (1987) argued that "the as a define article is a very important element to deconstructing and studying the text since it provides us with great knowledge to control the consistency of the text and understand its ambiguity i.e., the title grows and reproduces itself to identity the literary text, including the poem" (p.72). Considering the lexical meaning and derivations of the word title, it is found that it is derived from the meaning and interpretation, i.e., the title describes something and carries the meaning of that thing. The title of something in itself is the characteristic of that thing, its meaning and purpose. Allah says: "their mark [i.e., sign] is on their faces [i.e., foreheads] from the trace of prostration" (Qur'an: 48: 29). This verse refers to that there is a similarity between the linguistic meaning of the title and its idiomatic and semantic meaning. Thus, the title is considered procedural key in interpreting the literary text at semantic and symbolic levels. It is also considered the essence and main guide of the literary text and its reference point. The title often includes productive dimensions, indicates a referral sign and the writer's intention. It sometimes reflects some ideological and aesthetic purposes. In line with this frame of reference, Jamil Hamdaoui (1997) states that, "the title is a fundamental key which helps the reader to access the deep meanings of the text to interrogate and interpret it" (p. 96).

Having investigated the selected texts of this paper, we find that the title is conveyed by a nominal sentence of its informative entailment that reflects the strength of the nominal connotation on the one hand and its cognitive impact on the other hand (Eweis, 1987, p. 27). Semiotically, the writer chooses this title, Faces in Hot Water, to properly address the issue of the study to represent the suffering of a group of Palestinian workers working in a Jewish factory. For instance, Tayeh portrays Palestinian workers 'suffering and exhaustion at workplace. The writer's narrative style ensures that the title reflects the novel content and themes as well as vision to draw the reader's attention to Palestinian workers' suffering. The title can be divided into two parts. In the first part, "faces in hot water", the writer portrays "faces" as an independent part to achieve an emotional impact on the recipient. This is indeed achieved through the second part "in hot water".

Despite the inconsistent title part, the letters of the title partially suggest/represent a regular rhythmic phoneme reflecting a feeling of frustration, pain and suffering in the soul. The second title part is longer than the first. The meaning entailed by the novel conveyed through the semantic value of the title as well as the phonological division. The writer has formulated the title 
with its unique structure and semantic image to acquire an intellectual value, referring to the meaning that the title implies. This thus, links the narrative content of the novel and provides a description of the main characters' experiences in the novel. The semantic implication of the word "faces" used in the novel is the main axis in directing the reader's vision in understanding the sense of the main character's pain, frustration and suffering narrated and embodied in the novel. Such an implication, thereby, represents the contextual link between the title and the events performed by the characters. For instance, the writer diagnosed the feelings of pain and frustration through the characters. This is clear in the words of Ismail al-Ajmawi:

My eyes are tired of reviewing statements, significant numbers and statistics and checking bills, and with the first step I take in the street my feeling grows more tired .... My feelings of sadness and resentment overflow, and I feel myself lost and the days of my life are wasted on working on files and numbers.... The more my salary increases, the prices diverge greatly. (Tayeh, 1996, p. 4)

Through Ismail the writer includes those feelings in a special emotional, linguistic context. At other times, the writer brings those feelings up in the form of a virtue of this character. In this framework, "Ismael comes out of himself... Ismael al-Ajmawi raises his head loudly to the point of the voice ... Ezra stands tall in front of him broadly ... He stands in a defiant confronting Ismail... "Is it forbidden to smoke a cigarette?" Shouted, his thoughts filled him with an emotional charge" (Tayeh, 1996, p. 29). Furthermore, the writer shows the character's active feelings in the narrative text. To illustrate, "Ismail Al-Ajmawi throws the folded newspaper carelessly aside, taking off his shoes that looked dusty from the dust of the alley and the long walk across Omar Al-Mukhtar Street .... Then he sits waiting for food" (Tayeh, 1996, p. 5). Here, such a clear angry action by Ismail reflects the "hot water" in the title. To sum up, with regard to the semiotics of the title, it can be said that such ideas that Abdallah Tayeh comes up with in the fictional text relate to the title contextually. The content of "Faces in Hot Water" contextually entails meanings, concepts, events and visions within the novel. This, thus, contributes to building up a large part within the narrative framework of the novel.

\section{The Book Cover's Semiotic Analysis}

In the modern era, with the advancement of the print form of the book cover picture and the body of the literary text, a large number of (many) novelists began to compete in producing the aesthetics and connotations of the cover picture, or what some call the first threshold of the text. Due to the recent large number of novel productions, the recipient/reader tries to read the cover picture of the book. Such an analytical semantic reading as the first threshold enables the reader to understand the dimensions entailed within the cognitive structure of the narrative text. Many novelists choose their novel's cover picture to fit the fictional narrative so that it can be described in writing. So, we find that the picture of cover intersects with the body of the novel in many situations within the written text.

In the light of the foregoing, we realise that the book cover picture should transform the written experience within the literary text into a visual experience. The cover may produce this indication (sign) when it integrates into a specific format to enable it to produce that connotation. In this context, Said Bengrad (2003) emphasizes that inside the cover picture, a group of graphics, lines and colours may be found and each of which aesthetically convey a special meaning. Those patterns combine/integrate together to create connotations based on a cultural background expressed by the realistic experience within the novel (p. 35).

Looking at the pictures accompanying Faces in Hot Water, it is found that the picture has a rectangle form with two unequal dimensions, length and width. Through these two unequal dimensions, the writer may intend to represent the two heterogenous characters, the Palestinian and the Jewish. Having embodied the four equal angles for the rectangle, Tayeh's main goal is to symbolize the human dimension of equality. With regard to the colours used, it ought to be pointed that the colour perception remains related to a specific culture. While, for instance, symbolizes sadness in a people's culture, it may stand for optimism in another people's culture. This means that colour does not have a connotation common to all humans but its connotational signs differ from culture to another.

With regard to Faces in Hot Water, the writer used a group on indicative colours in/on the cover picture of the novel. He used black, blue, yellow and white, which is the most dominant in the picture. The black, used to define the painting, refers to the living reality of the Palestinians. Blue stands for coldness, water, or sky. Yellow stands for the sun and heat and sometimes illness and debility. These colours thus cover the different shades of meanings conveyed by the title. White, the most prominent colour, covers a large area of the novel cover to refer to Palestinians' simple and pure personality. This connotational image conveyed by the dominant white may refer to the dominant Palestinian part in the novel compared to Jewish characters.

Some of the lines and drawings on the cover are slanted up to 45 degrees to indicate fatigue. The scattered lines and triangles on the novel cover refer to Palestinian heritage as a reflection of the Palestinian diaspora and the division of the nation's unity. This symbolizes the barriers between the cities in Palestine. Similarly, the scattered circles indicate the prevailing customs and traditions in the villages of Palestine and their difference from one town to another. 
As for the other drawings on the cover, they are similar in many aspects to a human being. Seeing the drawings enable us to relate them to a human being since they embody a human figure or a shape close to it. However, drawings can not be determined by gender, colours, or even a certain age. We cannot also confirm that the drawing refers only for a child, a girl, an old man, a young man, a woman or a man. Some external characteristics such as length colours, or the shape of the eyes are unable to extract from the drawings. This shows the writer's satisfaction with the coordination between the lines to assure us that the matter is related to a human being rather than a tree or a bird. Having started with this drawing to avoid any racial intolerance or any kind of discrimination, the writer attempts to simplify reality by evoking this simplistic human version to unite human beings regardless of their colour or race. The shape of the hand in the picture demonstrates a specific condition that can be interpreted as a process of silencing the sound. Hiding the head expresses one's fear of something, which thus reflects state of fear that dominates the Palestinian characters in the novel. The shape of the feet anchored in the ground as represented on the cover represents the feeling of entrenchment in this land. It also symbolizes a challenge.

These movements remain universal since they express static human emotional cases. Yet, they still reflect the cultural character and the cultural nature of the Palestinian people. Through the drawing, it seems that the artist was clearly influenced by the time and place of the novel that deals with the issue of the Palestinian workers having struggled to earn a living stained with blood.

From the above, we find that the artist wants to express and embody the political and intellectual situation through the image of the book cover to meet directly with the topic of the novel and its cause. There are other things implying political and intellectual connotations adjacent to the idea of the novel as well. This assures that there is a large part of the narrative space having been reduced within the cover. It is possible in all cases for the analysis to be infinite. It is clear that the symbolic cover of the novel indicates shapes and colours whose individual depth is emphasised cover directly related to the body text.

\section{Characters' Semiotic Analysis}

This section discusses the semiotics of the characters and sheds light on the names, narrative functions, and characters' internal and external structure. A careful study of the characters' semiotic can become a fundamental determinant of the narrative story and the development of events within the novel. This semiotics becomes an active element in the novel development and in the characters' nature and relationship with one another.

This study deals with the semiotic analysis of each character separately. We will divide these characters into two groups, the Palestinian characters and the Jewish characters. To analyse the study characters, we will not refer to all characters mentioned in the novel; rather, we will limit the analysis to the protagonists and other main characters based on the extent of the dynamism of these characters and their role.

\subsection{Semiotic Analysis of Palestinian Characters}

The first character we have analysed in this study is the protagonist of the story, Ismail al-Ajmawi, who is mentioned more than 111 times. In the Arab heritage, this name bears a set of specific connotations and features that Al-Jahiz spoke about in more than one place in his book, The Animals. The choice of the writer of Ismail Al-Ajmawi might not be a spontaneous choice, rather intentionally selected to use him as a reference in referring to certain connotations. Ismail as a name has a unique reference in the Arab intellectual heritage since he is the "father of Arab". Al-Ajmawi was one of the ancient Palestinian neighbourhoods in Jaffa located on the Mediterranean coast. In relation to the Jewish Character Shmueli, semiotics is more clearly discussed.

Ismail, as any other Palestinian, was a government employee suffering from insufficient wages not enough for him and his family basic needs. So, he is forced to work in a factory owned by Ezra and Shmueli. It is, in fact, obvious that the writer does not focus too much on the external characteristics of Ismail. The writer describes him briefly "when he goes to the job, he wears a tie, when he goes to work inside the green line he wears a cap and he carries a bundle in his hand like other workers" (Tayeh, 1996, p. 110). The writer pays special attention to the internal characteristics of Ismail, focusing the internal description of his personality to stand up to its internal structure. Indeed, Tayeh's purpose behind this focus is to crystallize a group of feelings that will frame the personality of Ismail afterwards.

The writer begins his writing about Ismail through an internal monologue to reveal the internal, self-characteristics more clearly. In this regard, Tayeh states that "numerous thoughts run through his mind... My eyes are tired of reviewing statements, huge numbers and statistic and checking bills, and with the first step I take in the street my feeling grows more tired .... My feelings of sadness and resentment overflow, and I feel myself lost" (p. 4). The author recounts this internal dialogue to show the depths of al-Ajmawi character to highlight his virtues and distinguishes him from other characters in the novel. It is found that this character is unique at both social and cultural levels. This shows how the writer was planning to narrate the story through this internal dialogue. The writer starts portraying Ismail's daily suffering by expressing his exhaustion, pain and suffering at physical 
and emotional levels. The writer, for instance, narrates that "The more my salary increases, the prices diverge greatly.... A successive madness... A successive heartbreak, demands increase and the salary is limited" (Tayeh, 1996, p. 4). Feelings of frustration and suffering began increasing in Ismail more and more. Hence, the writer embodies these feelings through actions. Here, Tayeh (1996) states that, "Ismail Al-Ajmawi throws the folded newspaper carelessly aside, taking off his shoes that looked dusty from the dust of the alley" (p. 5). Al-Ajmawi feels successive frustration since his conditions do not meet his expectations.

Two dimensions of Ismael's feelings of frustration can be identified: a fixed (permanent) dimension represented in the concept of frustration as a feeling and an unfixed (temporary) dimension each time the writer makes the personality of Ismail a frame for it. Conceivably the writer, through the semiotics of the name Ismail, the semiotics of the situation and the feeling of frustration attributed to this character, wants to present the educated Palestinian living in frustration after the $1967^{\text {th }}$ War. Hence, the writer is found all time focus on narrating this character throughout. This thereby shows higher level of the internal description than the external one. So, the feelings of frustration and its experience are all emotions that hardly depart from Ismail Al-Ajmawi in every narrative situation within the novel. Through the personality of Ismail, the writer wants to tell us the reality of life that Palestinians living or were live after the war.

The second person the study sheds light on is Sabri Abu Shehadeh. This personality is considered an important axis of the fictional event since he is meant to symbolize many semiotic dimensions. In addition to the character of Al-Ajmawi, Abu Shehadeh is considered one of the main characters in the novel because their roles develop the plot and move the indicative idea within the narrative text. In this context, Mohammed Youssef Najm (1965) stated that, "The character is often the most important element in the story. It is also the axis around which the events revolve, as it affects the composition of the story with new developed aspects and sheds light on its secrets and depths" (p. 20).

Analysing the semiotic structure of Abu Shehadeh, we will explore many of the semantic connotations that this name carries since it fits in the narrative situation. So, the name Sabri in Arabic means the ability to bear and endure while Shehadeh means begging. That the writer gives such a name to his characters represents fatigue reflecting the condition of the Palestinian workers who lived during the War period, begging the Jewish employers to provide them work. Since the $1967^{\text {th }}$ War, specifically in the late seventies, there was a large number of workers who were directly linked to the Israeli economy began to establish a large segment of the Palestinian society. This social class represented most of the Palestinian workers.

The novel portrays another type of Palestinian suffering that workers started noticing Israeli employers turning into friends and not any more being enemies. The novel portrays that Abu Shehadeh suffers from the unhealthy relationships between him and his Jewish master in the factory. Nevertheless, there are other stronger reasons that affect the soul and life of Abu Shehadeh negatively i.e., feeling of dominant fear that appears through the narrative of Abu Shehadeh, as if the writer is trying to demonstrate another case of psychological disruption that this character has been experiencing. By portraying Abu Shehadeh's psychological case, Tayeh reflects the psychological features of the Palestinian people during the war, which represents the essence of the prevailing social situation. Within this frame of reference, Tayeh states that "a long line of cars and buses at the checkpoint. The sun has not risen yet, but the vision has begun to become clear.... Sabri Abu Shehadeh sits silently smoking a cigarette, inhaling and blowing out the smoke... The bus's atmosphere is full of smoke as if the bus is turning into a big cigarette and there are many smokers inside...." (pp. 91-92). The author also describes Abu Shehadeh's fear of the work manager, saying:

Sabri Abu Shehadeh leaves the factory with a group of workers and headed to where Ismail sits with some other workers to eat breakfast.... They sit together eating while the gazes of some Jewish labour officials, who have never seen such a gathering at breakfast, watching them. .... And the important thing is that Abu Shehadeh, Sabri and other workers do not desire (want) to go back to work. So the officials get angry and run to them after each other.... The factory manager first runs to explore the matter and looks at them harshly and defiantly

"Who refuses to work?"

"Not one" Sabri Abu Shehadeh replies promptly. (pp. 96-97)

The writer uses this dialogue to express the situations dynamically. Actually, if the writer prolonged the dialogue, he would make his idea clearer. Nevertheless, the author gives this short dialogue to clarify the idea in its various forms, indicating the nature of the relationship between the Palestinian "self" and the Jewish "other". Despite the message being short, Tayeh reveals the nature of the Jewish character characterized by tyranny and authoritarianism. Meanwhile, the writer manifests how scared Abu Shehadeh is. This could be clear when the latter responds, "there is no one". Abu Shehadeh's fear becomes more evident when having been fired for two weeks. To illustrate, "Abu Shehadeh goes out angry at Shmueli Rabinovitch. His work ends in the evening, so he and some of the other workers receive a document to leave for a two-week vacation.... The way back is long... The time passes slowly sad.... Abu Shehadeh gets angry.... Everything is falling in front of his eyes" (Tayeh, 1996, p. 101). 
Finally, through the character of Sabri Abu Shehadeh, the writer crystallizes his vision within the novel into something more concrete. This is clear when he makes Abu Shehadeh search for a job as an alternative to the previous work, so he turns one of his rooms into a store to sell vegetables.

The writer has worked to make these two characters Al-Ajmawi and Abu Shehadeh an example to embody experiences of torment, pain, frustration, fear and psychological disruption. At the same time, the two characters deeply express a great deal of self-hope. Al-Ajmawi and Abu Shehadeh strive hard to change their conditions. Their success or failure, however, remain dependent on the development of the events and type of relationships. This was evident at the end of the events when, for instance, Sabri Abu Shehadeh thinks about trying another job until he returns to his previous work, saying to himself:

Why not demolish the facade of the room overlooking the street to become a store like the rest of the market shops, in which I sell vegetables and fruits until I return to work after the vacation has expired. If I return, my wife occupies it; and if Shmueli fired me, I use it until I find a job. (Tayeh, 1996, p. 109)

The writer works on employing certain behaviours semiotically to express a general situation rather than a special case. In this case, writer works to expand the personality space by generalizing behaviour. This is obvious in the previous presentation of Abu Shehadeh's and Al-Ajmawi behaviours. Both Abu Shehadeh's and Al-Ajmawi behaviours cannot be viewed as an individual based behaviour. It should rather be treated as a human experience resulting from the relationships within Palestinian society. Such an experience is embodied in Abu Shehadeh's sense of fear and al-Ajmawi's sense of frustration. The writer tries first to find a refined background and reasons for these feelings. He then tries to embody Abu Shehadeh's and Al-Ajmawi's feelings and actions. The writer here reflects Palestinian society through these signs of the culture of fear and frustration that the Palestinians subsequently express. Thus, thus, led to the first Palestinian intifada.

Abu Ali, the third prominent character in this study and the most frequent number, who is mentioned more than 182 times in the novel. In Palestinian culture, Abu Ali is a nickname given to one being arrogant and imposing his opinion on others by force. The writer employs Abu Ali, an exploiter of Palestinian under-aged workers, to portray negative virtues as, narrated in the novel. Therefore, we find Tayeh describes this character externally as:

"You see, O Khamis!" Abu Darwish says.

"God does not bless him.... Look at his stomach.... and his head." Khamis replies

"It feels like an inflatable puff."

"Inflated with the blood and fatigue of the workers."

"God has permitted work and prohibited exploitation."

"He exploits whoever! He exploits the children of his neighbourhood, his neighbours and his family." (Tayeh, 1996, p. 20)

When Tayeh describes the personality of Abu Ali, he provides an accurate description through the connotation of the name in line with his arrogant behaviour with under-aged workers. These behaviours are related to the workplace and his family. This is clear in the narrative when he was trying to marry a second wife. The writer describes Abu Ali as a man of control, coercion, arrogance and exploitation. This is clear when Tayeh refers to Abu Ali as a man with a set of special behaviours within the narrative text. This shows a complete picture of this predator (Abu Ali). Thus, the writer has worked on referring to the abused group. This is done by the negative image of Abu Ali in the Palestinian society as well as the workplace.

Abu Darwish is one of the main characters in this novel. Metaphorically, Abu Darwish in the Palestinian intellectual and cultural heritage means a beloved good man. It is possible that the writer's use of Abu Darwish character is to generally portray the real character of Palestinians. Tayeh gives this character a social and cultural function of purity and serenity, which symbolizes the value of religion. Throughout the narrative writing, Abu Darwish is used to often infer his speech with some verses of the Qur'an. To demonstrates, "the workers' transport vehicle owned by the labor contractor Abu Ali stops in front of the café.... Abu Darwish sees him and recites in a low voice: 'Woe to every scorner and mocker. Who collects wealth and [continuously] counts it' (Qur'an: 104: 1-2)" (Tayeh, 1996, p. 37).

The author uses Surat Al-AlHumaza1 as a source for a set of characteristics of many static concepts and images within Abu Darwish and Abu Ali's characters. This does accordingly with contentment and exploitation. Hence, the author makes a clear distinction between those who earn a living by self-effort and hard work and between those earning a living by taking an advantage of others. The writer makes use of some Qur'anic verses in the narrative text which. These verses are completely separate in time and place, but they are linked directly to the situations related to Abu Darwish.

Saada, Ismail al-Ajmawi's wife, was among the active characters in Faces in Hot Water despite not being frequently mentioned. Saada means happiness and tranquillity. The writer uses Saada to highlight the positive role of the Palestinian woman. As

Page | 85 
narrated, Saada sews and sells clothes to help her husband to provide a better life for their children. The writer tries to expand the connotational value of Saada to reflect the feminine role in Palestinian society. Another example portraying the role of Palestinian women is Umm Mahmoud, the wife of Khamis Al-Haddad. As narrated, she sells lupinus (plant) to help her husband provide for the family. Similar to Saada and Umm Mahmoud, Abu Shehadeh's wife is another woman who helps her husband in the shop.

\subsection{Semiotic Analysis of Jewish Characters}

Contrary to the Palestinian characters having been discussed, the writer represents the Jewish characters as the "other" through the two personalities, Ezra and Shmueli Rabinovitch. The writer uses these characters to reflect their sense of superiority over the inferior Palestinian "other".

Semiotically, Ezra a person holding the Jewish belief of the highest supremacy. Ezra is portrayed as a racist person considering himself one of "God's Chosen People". He is the one who called for the purification of the Israelites' race, believing that they are the master race. He also considered the marriage of a Jew to other people a departure from Judaism. Given what has been said, "The priest Ezra stood and said to them: 'You have transgressed and married foreign women to increase sins (iniquities) of Israel. So confess now your sins to your Lord, the God of your forefathers, seek his satisfaction, and isolate the other nations of the earth and foreign women" (Bible, 1986, p. 753).

Ezra is a narrative function fully consistent with the characteristics mentioned above. This shows us a clear picture of this character since the external characteristics coincide with the internal ones. Due to his ethnic background and religious beliefs, Ezra, as narrated in the story, underestimates the Arab workers. In this context, Tayeh (1996) writes:

Ezra Cohen became impatient with me and other Arab workers, and his resentment increased after his son was injured. Oh guy! Get away from us.

He says it again and again.... I say to him every time: And you get away from our land as well.

No .... We will not leave anywhere... If we leave, the violence and war will escalate

Ismael comes out of himself.... Ismael al-Ajmawi raises his head loudly to the point of the voice..... Ezra stands tall in front of him.... broadly... He stands in a defiant confronting Ismail. (pp. 28, 107).

The writer describes the physical features as well as the internal feelings and characteristics of Ezra. Tayeh narrates Ezra's inner world to indirectly confirm the significance of this personality, reflecting contradiction and hostility against Arabs. This is due to both Jews' illegal dispossession of the Palestinian land and racial as well as religious differences. The evidence for this meaning is very clear in Ismail's response to Ezra: "And you get away from our land" (Ibid).

Semiotically, Ezra a person holding the Jewish belief of the highest supremacy. Ezra is portrayed as a racist person considering himself one of "God's Chosen People". He is the one who called for the purification of the Israelites' race, believing that they are the master race. He also considered the marriage of a Jew to other people a departure from Judaism. Given what has been said, "The priest Ezra stood and said to them: 'You have transgressed and married foreign women to increase sins (iniquities) of Israel. So confess now your sins to your Lord, the God of your forefathers, seek his satisfaction, and isolate the other nations of the earth and foreign women" (Bible, 1986, p. 753).

Ezra is a narrative function fully consistent with the aforementioned characteristics. This shows us a clear picture of this character since the external characteristics coincide with the internal ones. Due to his ethnic background and religious beliefs, Ezra, as narrated in the story, underestimates the Arab workers. In this context, Tayeh (1996) writes:

Ezra Cohen became impatient with other Arab workers and me, and his resentment increased after his son was injured.

Oh guy! Get away from us.

He says it again and again.... I say to him every time: And you get away from our land as well.

No .... We will not leave anywhere... If we leave, the violence and war will escalate

Ismael comes out of himself.... Ismael al-Ajmawi raises his head loudly to the point of the voice..... Ezra stands tall in front of him.... broadly... He stands in a defiant confronting Ismail. (pp. 28, 107).

The writer describes the physical features as well as the internal feelings and characteristics of Ezra. Tayeh narrates Ezra's inner world to indirectly confirm the significance of this personality, reflecting contradiction and hostility against Arabs. This is due to both Jews' illegal dispossession of the Palestinian land and racial as well as religious differences. The evidence for this meaning is very clear in Ismail's response to Ezra: "And you get away from our land" (Ibid).

The second Jewish character analyzed in this study is Shmueli Rabinovitch. Shmueli means Ismail in Arabic. It seems that the writer here wants to convey a paradoxical image between Ismail al-Ajmawi and Shmueli Rabinovitch. As mentioned before, Al- 
Ajami is one of the ancient Jaffa's neighbourhoods. This entails the writer's confession of the fact that Ismael was a citizen in Palestine. Tayeh gives Rabinovitch, which is a Polish name, as a nickname to Shmueli (Ismael) to show that the latter does not belong to Palestine. To know what is "the connotation of consort we must move to a higher level 'the actions of characters or narration" (Akar et all., 1992, p. 27).

The writer's consciousness is reflected in the indirect controversy between the Palestinian "self" and the Jewish "other". This consciousness is evident through the actions of Ismail and Shmueli. Tayeh may refer here, to another general vision beyond the scope of this novel to reflect the relationship between Palestinians and Jewish. But the writer also takes advantage of the semiotics of the name to produce new desired connotations and thereby deepens these connotations with some similar situations when describing the depth of the gap between the Eastern and Western Jews. This seems clear from Ezra's words on Shmueli:

"Shmueli has children on the border, O Ezra""

Ezra mockingly replies: "You are crazy, his children are in America."

"So, he is not afraid of his children like you and me." (Tayeh, 1996, p. 108)

Through the characters 'previous presentation and analysis, it is noted that these characters stand for a set of intersections, adding deep intellectual dimensions, which are static and constant within the writer's consciousness. These dimensions create numerous connotations that help in embodying the novel idea and vision.

\section{Semiotic Analysis of Settings (Time and place)}

The novel's temporal and spatial framework is directly related to the writer's vision and the novel main theme. Time and place are not usually abstract but rather have multiple artistic and thematic connotations. They embody the narrative and social environment surrounding the characters in the story. Accordingly, time and place play an important role in the characters' existence, which helps shape their attitudes, values, actions, attributes, and ways of life. Thus, time and space entail a semantic function and describe the occurrence of events in a space that accommodates and affects the structure of the novel and gives it other semantic connotations. Whoever reads the novel Faces in Hot Water, he notices that the writer develops and embeds multiple places in the story to suit the plot's development and the movement of different events which need multiple places. So, the event is characterized by extravagance. The writer deals with a set of characters' dramatic moments to portray the character's personalities. Therefore, we find some narrated characters polarizing the events in a non-short period of time and in a multiple spatial space. The place and time overlap clearly from the beginning of the novel:

'The deep silence of the city erupts with noise and clamour before the dawn call to prayer in Shuja'iyya Square There is a temporary station from which workers rush to work inside. They yawn in in order to avoid sleep and drowsiness from their minds. The lights are spread by light poles and the lanterns of cars and buses. Darkness spreads in the sides of the square and illuminates parts of the green grass while another parts remain hidden in the darkness. The lights are shining in the courtyard of the city police station. Horns are louder ... the noise and friction sounds of the rubber wheels with the asphalt louder. The vendors' calls and the voices of the trolley drivers are echoing, as each of them is calling ... Jaffa ... Ashdod ... Tel Aviv.... (Tayeh, 1996, pp. 1-2)

The author was aware of picking the right time to express the reality of the Palestinian workers 'suffering. He chooses a moment before the dawn call to prayer to show the depth of the workers 'suffering. And this quotation - like the rest of the text - is dominated by the present tense. The temporal syntactic tense remains the same along the story to fit the narration time. That the writer describes how Palestinian workers start their day has a clear effect on both the characters 'fate as well as time and place relationship.

The author's account of the accurate depiction of the taxi yard comprehensively shows penetration of temporal and spatial relationships regarding accidents and personality perspective. It seems that the writer has made use of these details to create extensions of time and place in the reader's mind. This means that the narrative space is formulated in multiple places. This indicates that the place is not merely an objective and neutral place. It is rather of artistic fiction that enables the writer to depict the interaction between the characters to create new concepts and other visions. For instance, Tayeh (1996) writes "I do not sell vegetables and fruits in the market. Why not demolish the facade of the room overlooking the street to become a store like the rest of the market shops, in which I sell vegetables and fruits until I return to work after the vacation has expired" (p. 28). 
The writer emphasizes the concept of a proper alternative to justify Palestinian's earning compared to the humiliation that Palestinian workers are exposed to by the Jewish administration. It is noticeable that the writer focuses on one specific time in narrating Sabri Abu Shehadeh's decision. In addition to the time related to the event, we can distinguish another level of time the psychological time where times (the present, past and future) overlap and intersect. The writer, here, has deviated from the direct path of narration based on the known chronology; and makes the characters go back in some events to the distant/recent past once again even though the character in the novel lives in the present time:

Finally, the five years have passed with no change as the patient's death is difficult and slow, or as the death of martyrdom is fast and comfortable. [Abu Shehadeh continues sarcastically] You go out from the small detention center surrounded by wires, cold walls, narrow prison cells, crowded corridors and constant dampness (humidity), to the large prison in the camp, the factory and the neighborhood where you see the wires with your own eyes.... So, you shrink or rebel behind the walls. But here the wires are inside you, live in you, walk on your feet, spread inside you, so they do not leave you and you have no escape from them. All you have to do is choose to be inside the small detention center or to be inside the big detention camp. (Tayeh, 1996, pp. 73-74)

Tayeh here flashes back to the past, tells us the experience of Sabri Abu Shehadeh in prison and moves to the future. He extracts some events to depict and talk about in the present. The lack of chronology in such situations is due to the writer's awareness to tell us about some hidden aspects in the lives of many narrative (narrated) characters. Here, Abu Shehadeh tries to evoke this past from his life so that he may be able to face the harsh present. The writer wants, through this interruption of chronological sequence which is often repeated in the novel, to introduce us to the past of these characters or at least to find out some of the main points in their lives to explain their positions towards the present. The intersections of time that Abu Shehadeh lives during this period helps him to describe the state of suffering that he has been experiencing as well as the heroic past that he lived. He also tries to escape from the suffering of the less heroic present to the more heroic past. While human being always avoids the agony moment and tries to minimize it as short as possible, (s) he prolongs the discussion about the beautiful moment and wishes it to last.

It was for the writer to use semiotic dimensions to portray taxis yard in Gaza City. In line with the manifestation of the description, the place hints at a lack of reassurance, symbolizes the changing situation and stands up for the lifestyle of Palestinian workers. This becomes clearer when the writer talks about the conditions of the workers during their work in the factory and the moment they return to their homes. The writer, for instance, states that:

Since the Palestinian worker arrived at the factory of shovelling piles of cans, he secretly called upon God for the machine's breakdown or the tractor's obstruction and an electricity defect but it gets brighter. His supplications are not answered. In the factory, he runs, thrusts his fingers and hands together, takes out the full cardboard boxes and replaces them with the empty ones, sweats and puffs in exasperation as he finds it difficult to continue. (Tayeh, 1996, p. 26)

The author's description of the factory indicates the lack of the necessary, natural and decent life that any ordinary person seeks. The workplace is where workers repel since it lacks the necessary conditions that humans need for a good life. The writer's description of the place, here, indicates more psychological significance than the actual situation. This is confirmed when he describes the moment the workers return to the home. The writer, for instance, states that:

The bus approaches the intersection of the roads leading to Al-Majdal [a Palestinian city] and the driver lowers the speed with successive pressures on the brake. The light signal is green. .... The driver continues to rush south to Gaza, and the workers' heads swing (wobbling) sleepy and tired. ... Silence prevails on everyone inside the bus and is interrupted only by the sound of the engine bursting continuously. ... I open my eyes in 15 minutes and the sound of the engine is suddenly down. ... Look out the window. ... Yellow lights cover the square. ... Where are we? I am rubbing my eyes (I will have to do something about it). Ah, the checkpoint at Erez. (Tayeh, 1996, pp. 32-33)

In addition to the checkpoint at Erez, Tayeh has portrayed the yard of the taxi and the factory before. He described them within the temporal and spatial context to express a set of meanings of semiotic significance to refer to the daily suffering of the Palestinian workers. Interestingly, every time and every picture of the places mentioned by the writer suggests an indicative set of semiotics. This thus shows the extent of the suffering of the Palestinian workers who have no time to sleep and no place to rest. Nevertheless, the reader notices the writer's emphasis on the material and spiritual elements each time with remarkable 
renewal. This confirms that time and space, with all their previous details, have a semantic value. It is as if these places, especially the square, and these people (workers) are on the verge of a new situation of life. Thus, this miserable living reality would not continue.

\section{Conclusion}

This study has discussed all pivotal aspects of semiotic analysis of Faces in Hot Water. The researcher attempts to identify some of the intellectual, humanitarian and political issues that lie in the writer's consciousness. Thus, the researcher, through the main characters 'behaviour, wants to embody many feelings such as fear, frustration and suffering. The writer represents a complete cultural map of society that predicts the prevailing culture after the 1967 War. The study demonstrates that, despite the job/work vacancies and the decreasing poverty rate, it is clear that it is the culture of fear, frustration and agony that dominates society. It is found that Abdullah Tayeh, throughout the narrative has demonstrated this culture to reveal a set of rules that lead to emotional production revealed within the Palestinian society at that time. The researcher, through a set of questions directly related to the behaviours of the characters, realizes the consciousness prevailing within the Palestinian society.

This study has attempted to reveal the invisible relationships within the immediate event. To do so, the study has analysed the characters by investigating their internal and external structure, role and names, as well as expressing some of the implicit connotations and components behind these characters. The study has also analysed the elements of time, place, title and cover image. In each element, the study has examined the tools that the writer has used to produce the semiotics whose signs are explained in respect to shape the narrative space.

\section{References}

[1] Akar, A. H., \& Bashir, A., \& Hassan, B. (Trans). An Introduction to the Structural Analysis of Narrative by Roland Barthes. Morocco: Union of Moroccan Writers.

[2] Azra, S. (1986). Holy Bible $10^{\text {th }}$ ed., Jerusalem: World Bible Centre.

[3] Bengrad, S. (2003). Semiotics and Theory of Meaning. Rabat: Time Publications.

[4] Eweis, M. (1987). The Title in Arabic Literature: Concept's Genesis and Development. Cairo: The Anglo Egyptian Bookshop.

[5] Hamdaoui, J. (1997). Semiotics and the Title: The World of Thought. Journal of Arts and Literature, 5(3), 79-112.

[6] Haroun, A. S. (1969). El-Jahiz' Book of the Animal's Review. Beirut: Arab Book House.

[7] Miftah, M. (1987). The dynamic of the Text. Casablanca: Arab Cultural Centre.

[8] Najm, M. Y. (1965). The Story in Modern Arabic Literature. Beirut: House of Culture.

[9] Tankoul, A. (1987). Colonial Writing and Writing back or (Speech writing and writing the speech in crazy of pain, Journal of College of Literature and Human Sciences, 9.

[10] Tayeh, A. (1996). Faces in Hot Water. Gaza: The Palestinian Writers Union 